\section{Correspondence}

Sabrina Stefanello

Department of Medical

Psychology and Psychiatry

Faculty of Medicine, University of Campinas (UNICAMP)

Rua Tessália Vieira de Camargo 126 13081-970 Campinas SP - Brasil E-mail: sabrinas@fcm.unicamp.br binastefanello@yahoo.com.br

\section{Support}

This study was supported by Fundação de Amparo à Pesquisa do Estado de São Paulo [The State of São Paulo Research Sponsor Agency], grant n॰ 05/50636-2 Dr. Stefanello received research support from Pan-American Health Organization Dr. Botega received research support from Foundation for the Support of Research in the State of São Paulo and the World Health Organization. He serves as advisor on suicide prevention for the Brazilian Ministry of Health

Received 5 August 2010

Received in final form 3 December 2010 Accepted 10 December 2010

\title{
Depression and anxiety in a community sample with epilepsy in Brazil
}

\author{
Sabrina Stefanello' ${ }^{1}$ Letícia Marín-Léon², Paula Teixeira Fernandes³, \\ Li M. Li ${ }^{3}$ Neury José Botega ${ }^{1}$
}

\begin{abstract}
Objective: To estimate the frequency of depression/anxiety and to establish the social, epilepsy and psychiatric characteristics in individuals with epilepsy. Method: A crosssectional study was employed to evaluate 153 subjects with epilepsy who were identified in a previous community-based survey. First, a structured interview was conducted, followed by a psychiatric evaluation. Subjects with depression were compared to those without, and subjects with anxiety were compared to those without. Results: The prevalence of anxiety and depression was 39.4 and $24.4 \%$, respectively. Both were associated with low schooling (OR 3.8, 95\% Cl 1.6 to 9.0 and OR $2.8,95 \% \mathrm{Cl} 1.2$ to 6.5 for depression and anxiety, respectively), lifetime suicidal thoughts (OR 4.4, 95\% Cl 1.9 to 10.3 and OR 3.6, $95 \% \mathrm{Cl} 1.7$ to 7.7 ) and lifetime suicide attempts (OR 9.3, 95\% $\mathrm{Cl} 2.6$ to 32.8 and OR 6.9, $95 \% \mathrm{Cl} 1.8$ to 26.4). Conclusion: The high rates of depression and anxiety reinforced the need for recognition and treatment of mental disorders in epilepsy.
\end{abstract}

Key words: mood disorders, anxiety, depression, epilepsy, epidemiology, suicide attempt.

\section{Depressão e ansiedade na epilepsia: uma amostra da comunidade no Brasil}

\section{RESUMO}

Objetivo: Estimar a frequência de depressão/ansiedade em pessoas com epilepsia e estabelecer as características sociais, da epilepsia e psiquiátricas associadas. Método: Foi feito um estudo transversal para avaliar 153 sujeitos com epilepsia identificados em um levantamento prévio feito na comunidade. Primeiramente foi realizada uma entrevista estruturada, seguida de uma avaliação psiquiátrica. Os sujeitos deprimidos foram comparados com aqueles sem depressão e os sujeitos com ansiedade foram comparados com aqueles sem ela. Resultados: A prevalência de ansiedade e depressão foi de $39,4 \%$ e $24,4 \%$, respectivamente. Ambas foram associadas a baixa escolaridade (OR 3,8; IC95\% 1,6-9,0 e OR 2,8, IC95\% 1,2- 6,5 para depressão e ansiedade, respectivamente), ideação suicida (OR 4,4; IC95\% 1,9-10,3 e OR 3,6; IC95\% 1,7-7,7) e tentativa de suicídio (OR 9,3; IC95\% 2,6-32,8 e OR 6,9; IC95\% 1,8-26,4). Conclusão: As altas taxas de depressão e ansiedade reforçam a necessidade de reconhecimento e tratamento dos transtornos mentais na epilepsia.

Palavras-chave: transtornos do humor, ansiedade, depressão, epilepsia, epidemiologia, tentativa de suicídio.

It is becoming increasingly accepted that psychological disorders have a broad impact on individuals with epilepsy. Nonselected populations of people with epilepsy present consistently higher rates of psychiatric comorbidity compared to the general population ${ }^{1-3}$. Depression and anxiety disorders are the most frequent psychiatric comorbidities in epilepsy ${ }^{2-4}$. The lifetime prevalence of depres- 
sive disorder in epilepsy is unclear, varying from 8-48\% depending on the methodological approach ${ }^{4,5}$. In a Canadian population-based study, the life prevalence for anxiety and depressive disorders in people with epilepsy was $22.8 \%$ and $17.4 \%$, respectively ${ }^{3}$.

Depression in epilepsy has been associated with poor quality of life ${ }^{6,7}$, suicidal behavior ${ }^{8}$, poor seizure control ${ }^{9}$, unemployment ${ }^{9}$, presence of another chronic health condition $^{9}$, perception of stigma ${ }^{10}$ and effect of antiepileptic medication ${ }^{9}$. Although anxiety disorders have received less attention than mood disorders in patients with epilepsy, they have been associated with poor quality of life, ${ }^{11}$ lack of seizure control ${ }^{1,10,12}$ and earlier age onset of epilepsy ${ }^{1}$. Despite the impact and link of psychiatric disorders with epilepsy, they are all underrecognized and undertreated ${ }^{4,7}$.

Especially in developing countries, there is a lack of community studies regarding depression and anxiety in people with epilepsy. The objectives of this study were to estimate the frequencies of depression and anxiety and determine the social, epilepsy and psychiatric characteristics related with these disorders in people with epilepsy in a community sample in Brazil.

\section{METHOD}

\section{Study design and setting}

This was a cross-sectional study undertaken in Campinas, a city with 1.1 million inhabitants in the southeast of Brazil. The study was carried out at the district of Barão Geraldo, which has approximately 44,000 inhabitants. This area is comprised of 19 neighborhoods, a technological center and two universities. In contrast, in the same region, there are rural areas and neighborhoods characterized by low income.

\section{Subjects}

The data were collected between May 2006 and December 2007. An attempt was made to interview all 171 individuals who were 13 years or older and had been diagnosed with epilepsy in a previous community-based study (part of the Global Campaign Against Epilepsy, launched by the World Health Organization (WHO), the International League Against Epilepsy and the International Bureau for Epilepsy). In this study, the targeted population was surveyed door-to-door and screened or epilepsy, and suspected cases were confirmed by neurologists ${ }^{13}$.

\section{Instruments}

The questionnaire used in this survey was based on the WHO Multisite Intervention Study on Suicidal Behavior. This survey covers a series of socio-demographic, psychosocial and clinical variables. The following psychometric scales, each already validated in Brazil, were also included in the study.
The Hospital Anxiety and Depression Scale (HAD) covers psychological symptoms of anxiety and depression. This scale is comprised of 14 multiple-choice items regarding anxiety and depression. The cut-off points that were adopted for anxiety and depression were at eight and seven items positive (out of 14), respectively, as suggested by the Brazilian validation study ${ }^{14}$. These cut-off points provided $74 \%$ sensitivity as well as specificity for the anxiety parameter. For depression, the sensitivity and specificity were $85.7 \%$ and $72.4 \%$, respectively ${ }^{14}$.

The Global Assessment Scale (GAS) assesses the individual's general level of functioning. The evaluation was made by the interviewer. The scale ranges from 1 (the hypothetically sickest person) to 100 (the hypothetically healthiest person $)^{15,16}$. Subjects with scores ranging from 0 to 30 were classified as severe cases, scores ranging from 31 to 60 were classified as moderate cases and scores ranging from 61 to 100 were classified as mild/normal.

The Mini International Neuropsychiatry Interview (MINI) version 5.0.0 was used to provide diagnoses according to the Diagnostic and Statistical Manual of Mental Disorders - Fourth Edition (DSM-IV) criteria $^{17}$. The MINI is a structured diagnostic interview that is compatible with the DSM-III-R/IV and ICD-10 criteria ${ }^{17}$.

First, individuals were approached at their places of residence. A short-term interview with the HAD (read out for every patient) and the GAS were completed on that occasion. Second, for those who agreed, a new interview was scheduled at the university hospital. In this second interview, a detailed psychiatric evaluation, including the MINI, was performed by a trained psychiatrist. The first interview was conducted by seven trained interviewers: two psychology students, one medical student, two psychologists and two primary health care workers. The training of the interviewers included three 90-minute meetings and a pilot with questionnaire application. Meetings at regular intervals were held during the data gathering to ensure accurate classification of the subjects. No interrater reliability calculation was performed for this data.

\section{Definition of variables}

Active epilepsy - Any patient who has had recurrent unprovoked seizures with an interval of $24 \mathrm{~h}$ or more in the previous 24 months.

Inactive epilepsy - Any patient who has had recurrent unprovoked seizures with an interval between them of 24 h or more, but who has been seizure-free for the previous 24 months. Both active and inactive epilepsy were classified in accordance with previous study ${ }^{13}$.

Economic group - Sefined by the presence and number of various household items, weighted as per the Brazilian Association of Research Companies (ABEP) ${ }^{18}$. 
This index of economic classification is based on the power of consumption, a measure of personal material wealth ${ }^{18}$. Three groups were defined: low (0-13), middlelow (14-22) and middle-high / high (23-35). People in the low economic group did not have a car or a freezer, $69 \%$ of them had no electronic appliances, such as a video or DVD, and 59\% did not possess a refrigerator.

Occupational status - Was categorized in active (full, part-time or temporary employment or student), inactive (retired, unemployed or never had a job) and homemaker.

\section{Statistical analysis}

Subjects were classified as cases and non-cases of depressive and anxiety disorders based on their HAD scores. The independent variables in the analysis included socio-demographic, psychosocial and clinical variables and questions about suicidal behavior. Logistic regression analysis was used to compare those cases and non-cases of depressive and anxiety disorders using crude odds ratios (ORs) and 95\% confidence intervals (CIs). All analyses were conducted using STATA version 8.0 (StataCorp, College Station, TX, USA).

Table 1. Demographic, social, occupational and economic characteristics of people with epilepsy who were depressed ( $n=32)$, not depressed $(n=99)$, anxious ( $n=50)$ and not anxious $(n=77)$.

\begin{tabular}{|c|c|c|c|c|c|c|c|c|c|c|c|c|c|c|}
\hline \multirow[b]{3}{*}{ Variables } & \multicolumn{7}{|c|}{ Depression } & \multicolumn{7}{|c|}{ Anxiety } \\
\hline & \multicolumn{2}{|c|}{ Yes } & \multicolumn{2}{|c|}{ No } & \multirow[b]{2}{*}{$\mathrm{OR}^{+}$} & \multirow[b]{2}{*}{$95 \% \mathrm{Cl}^{\ddagger}$} & \multirow[b]{2}{*}{$P$ value } & \multicolumn{2}{|c|}{ Yes } & \multicolumn{2}{|c|}{ No } & \multirow[b]{2}{*}{$\mathrm{OR}^{+}$} & \multirow[b]{2}{*}{$95 \% \mathrm{Cl}^{\ddagger}$} & \multirow[b]{2}{*}{$P$ value } \\
\hline & $\mathrm{N}$ & $\%$ & $\mathrm{~N}$ & $\%$ & & & & $\mathrm{~N}$ & $\%$ & $\mathrm{~N}$ & $\%$ & & & \\
\hline Sex & & & & & & & 0.7 & & & & & & & 0.01 \\
\hline Male & 17 & 53.1 & 49 & 49.5 & 1.0 & & & 18 & 36.0 & 45 & 58.4 & 1.0 & & \\
\hline Female & 15 & 46.9 & 50 & 50.5 & 0.9 & $0.4-1.9$ & & 32 & 64.0 & 32 & 41.6 & 2.5 & $1.2-5.2$ & \\
\hline Total & 32 & 100 & 99 & 100 & & & & 50 & 100 & 77 & 100 & & & \\
\hline Age bracket & & & & & & & $<0.0001$ & & & & & & & 0.6 \\
\hline $13-41$ & 8 & 25 & 61 & 61.6 & 1.0 & & & 27 & 54 & 38 & 49.4 & 1.0 & & \\
\hline $42+$ & 24 & 75 & 38 & 38.4 & 4.8 & $2.0-11.8$ & & 23 & 46 & 39 & 50.6 & 0.8 & $0.4-1.7$ & \\
\hline Total & 32 & 100 & 99 & 100 & & & & 50 & 100 & 77 & 100 & & & \\
\hline Schooling (years) & & & & & & & 0.002 & & & & & & & 0.02 \\
\hline$\geq 4$ & 18 & 56.3 & 82 & 82.8 & 1.0 & & & 33 & 66.0 & 65 & 84.4 & 1.0 & & \\
\hline $0<4$ & 14 & 43.7 & 17 & 17.2 & 3.8 & $1.6-9.0$ & & 17 & 34.0 & 12 & 15.6 & 2.8 & $1.2-6.5$ & \\
\hline Total & 32 & 100 & 99 & 100 & & & & 50 & 100 & 77 & 100 & & & \\
\hline Marital status & & & & & & & 0.04 & & & & & & & 0.9 \\
\hline $\begin{array}{l}\text { Married / Steady } \\
\text { relationship }\end{array}$ & 17 & 53.1 & 47 & 47.5 & 1.0 & & & 26 & 52.0 & 37 & 48.0 & 1.0 & & \\
\hline Single & 9 & 28.1 & 46 & 46.4 & 0.5 & $0.2-1.3$ & & 19 & 38.0 & 33 & 42.9 & 0.8 & $0.4-1.7$ & \\
\hline $\begin{array}{l}\text { Separated / } \\
\text { Divorced / Widow }\end{array}$ & 6 & 18.8 & 6 & 6.1 & 2.8 & $0.8-9.7$ & & 5 & 10.0 & 7 & 9.1 & 1.0 & $0.3-3.6$ & \\
\hline Total & 32 & 100 & 99 & 100 & & & & 50 & 100 & 77 & 100 & & & \\
\hline Occupation & & & & & & & 0.006 & & & & & & & 0.3 \\
\hline Active $^{\S}$ & 10 & 32.3 & 59 & 63.4 & 1.0 & & & 25 & 52.1 & 43 & 58.9 & 1.0 & & \\
\hline Housewife & 4 & 12.9 & 10 & 10.8 & 2.4 & $0.6-9.0$ & & 8 & 16.7 & 6 & 8.2 & 2.3 & $0.7-7.4$ & \\
\hline Inactive" & 17 & 54.8 & 24 & 25.8 & 4.9 & $1.7-10.4$ & & 15 & 31.2 & 24 & 32.9 & 1.1 & $0.5-2.4$ & \\
\hline Total & 31 & 100 & 93 & 100 & & & & 48 & 100 & 73 & 100 & & & \\
\hline Economic group & & & & & & & 0.2 & & & & & & & 0.05 \\
\hline Mid-high 23-35 & 3 & 10.0 & 24 & 24.2 & 1.0 & & & 5 & 10.4 & 21 & 27.3 & 1.0 & & \\
\hline Mid-low 14-22 & 19 & 63.3 & 59 & 59.6 & 2.6 & $0.7-9.5$ & & 30 & 62.5 & 44 & 57.1 & 2.9 & $1.0-8.4$ & \\
\hline Low 0-13 & 8 & 26.7 & 16 & 16.2 & 4.0 & $0.9-17.4$ & & 13 & 27.1 & 12 & 15.6 & 4.5 & $1.3-15.9$ & \\
\hline Total & 30 & 100 & 99 & 100 & & & & 48 & 100 & 77 & 100 & & & \\
\hline
\end{tabular}

${ }^{\dagger}$ OR: crude odds ratio; ${ }^{\ddagger} 95 \% \mathrm{Cl}: 95 \%$ confidence interval; ${ }^{5}$ Includes students; " Retired, unemployed or never had a job. 


\section{Ethical aspects}

The study was approved by the university's ethics committee (Comitê de Ética da Faculdade de Ciências Médicas da Universidade Estadual de Campinas). All subjects enrolled in the research agreed to participate and signed a consent form.

\section{RESULTS}

From the 171 individuals previously diagnosed with epilepsy, 153 were included in the present study (3 had died, 3 had moved and 12 refused to participate). Because of missing data from the HAD, 22 depression items and 26 anxiety items were excluded post hoc from the analyses. The MINI was used to evaluate the 111 individuals who came to the hospital for the diagnostic interview.

The HAD identified 32 (24.4\%) subjects as having depression and 50 (39.4\%) with an anxiety disorder. Being inactive (retired, unemployed or never had a job), fewer years of schooling and age above 41 years old were associated with depression. The female gender, fewer schooling years and being in the low economic group were associated with anxiety (Table 1).

Specific epilepsy characteristics are presented in Table 2. Only active epilepsy was found to be associated with depression. Psychiatric comorbidities are presented in Table 3. Both anxiety and depression were identified in 21 individuals (42.9\%). Lifetime suicidal thoughts and suicidal attempts were associated with both disorders, and lower scores on the GAS were associated with anxiety (Table 3).

\section{DISCUSSION}

Our findings indicated that individuals with epilepsy identified in a door-to-door survey have high frequencies of anxiety (39.4\%) and depression (24.4\%). They also have important variables associated with both depression and anxiety, such as lower schooling, a higher risk of suicidal behavior and the association of symptoms of both depression and anxiety.

The major strengths of our study are its community setting, the use of validated psychometric scales and the fact that it was carried out in a developing country with the diagnosis of epilepsy being confirmed by neurologists. Nevertheless, some potential limitations should be considered. The size of our sample did not allow for multiple regression analysis, which would have identified discriminators that may predispose individuals for depression and anxiety in epilepsy. Due to economic limitations and because our sample was derived from a previous survey, we had a limited number of participants. The possible occurrence of a type I error should therefore be kept in mind.
Other limitations of our study included interviewers who were not senior researchers and the lack of interrater reliability assessments. The diagnoses of depressive or anxiety disorders made during the screening phase of the study were not later confirmed, as it was considered operationally difficult to obtain a reliable assessment by means of a standardized psychiatric interview. Structured psychiatric interviews are reliable and efficient; however, they require considerable time and are not readily accessible to standard practice in a non-psychiatric environment. A comprehensive review found that HAD performed well in assessing the symptom-severity and caseness of depression and anxiety in somatic, psychiatric and primary care patients, as well as in the general population ${ }^{19}$. This review reported an optimal balance between sensitivity and specificity when caseness was defined by a score of 8 or above on both the anxiety and depression subscales ${ }^{19}$.

The frequencies of depression (24.4\%) and anxiety (39.4\%) encountered in our study are higher than the figures from a Canadian population-based study (17.4 and $22.8 \%$, respectively) ${ }^{3}$. In contrast, they are lower when compared to those found in West Africa, where the respective frequencies of depression and anxiety were 84 and $66 \%$ in Togo and 85.3 and $84.1 \%$ in Benin ${ }^{12}$. Methodological issues might have contributed to differences found, for example, in the questionnaires used to identify depression and anxiety. The Composite International $\mathrm{Di}$ agnostic Interview used in the Canadian study is a diagnostic interview for the assessment of mental disorders according to the definitions and criteria of the ICD-10 and DSM-IV. As a diagnostic instrument, it is expected to generate more restrictive diagnosis categories ${ }^{20}$. On the other hand, the Goldberg's Anxiety and Depression Scale used in Togo and Benin works best as a screening tool because of its high sensitivity (88-100\%) and lower specificity (33-68\%) to detect depression and anxiety ${ }^{21}$. The HAD applied in our sample is a screening tool designed for detecting depression and anxiety in general medical settings and has been used in community studies of psychological outcome in epilepsy ${ }^{1,922}$. We adopted the cutoff points of the validation because it achieved 74\% for both sensitivity and specificity for anxiety and 85.7 and $72.4 \%$, respectively, for depression ${ }^{14}$. Even though methodological issues might have contributed to the differences, socio-economic and cultural factors may also have a role in the way people answered the questions. Epilepsy is associated with stigmatization and the "treatment gap," especially in developing countries, is likely one of the most important causes of non stabilized seizures, which is also connected to depression and anxiety ${ }^{23}$.

Active epilepsy represented an almost 3-fold risk for depression. It has been suggested that recurrent seizures 
Table 2. Epilepsy characteristics in people with epilepsy who were depressed $(n=32)$, not depressed $(n=99)$, anxious $(n=50)$ and not anxious $(n=77)$.

\begin{tabular}{|c|c|c|c|c|c|c|c|c|c|c|c|c|c|c|}
\hline \multirow[b]{3}{*}{ Variables } & \multicolumn{7}{|c|}{ Depression } & \multicolumn{7}{|c|}{ Anxiety } \\
\hline & \multicolumn{2}{|c|}{ Yes } & \multicolumn{2}{|c|}{ No } & \multirow[b]{2}{*}{$\mathrm{OR}^{+}$} & \multirow[b]{2}{*}{$95 \% \mathrm{Cl}^{\ddagger}$} & \multirow[b]{2}{*}{$P$ value } & \multicolumn{2}{|c|}{ Yes } & \multicolumn{2}{|c|}{ No } & \multirow[b]{2}{*}{$\mathrm{OR}^{+}$} & \multirow[b]{2}{*}{$95 \% \mathrm{Cl}^{\ddagger}$} & \multirow[b]{2}{*}{$P$ value } \\
\hline & $\mathrm{N}$ & $\%$ & $\mathrm{~N}$ & $\%$ & & & & $\mathrm{~N}$ & $\%$ & $\mathrm{~N}$ & $\%$ & & & \\
\hline Type of seizure & & & & & & & 0.9 & & & & & & & 0.8 \\
\hline Partial - simple & 5 & 17.2 & 13 & 16.0 & 1.0 & & & 7 & 15.6 & 10 & 15.6 & 1.0 & & \\
\hline Partial - complex & 14 & 48.3 & 37 & 45.7 & 1.0 & $0.3-3.3$ & & 23 & 51.1 & 29 & 45.3 & 1.1 & $0.4-3.4$ & \\
\hline Generalized & 10 & 34.5 & 31 & 38.3 & 0.8 & $0.2-2.9$ & & 15 & 33.3 & 25 & 39.1 & 0.9 & $0.3-2.7$ & \\
\hline Total & 29 & 100 & 81 & 100 & & & & 45 & 100 & 64 & 100 & & & \\
\hline Age at first seizure & & & & & & & 0.08 & & & & & & & 0.8 \\
\hline$\leq 21$ years & 9 & 28.1 & 44 & 45.8 & 1.0 & & & 20 & 40.8 & 32 & 42.7 & 1.0 & & \\
\hline$>21$ years & 23 & 71.9 & 52 & 54.2 & 2.2 & $0.9-5.1$ & & 29 & 59.2 & 43 & 57.3 & 1.1 & $0.5-2.2$ & \\
\hline Total & 32 & 100 & 96 & 100 & & & & 49 & 100 & 75 & 100 & & & \\
\hline Active epilepsy & & & & & & & 0.03 & & & & & & & 0.3 \\
\hline No & 9 & 30.0 & 49 & 53.3 & 1.0 & & & 20 & 42.5 & 37 & 52.1 & 1.0 & & \\
\hline Yes & 21 & 70.0 & 43 & 46.7 & 2.7 & $1.1-6.4$ & & 27 & 57.5 & 34 & 47.9 & 1.5 & $0.7-3.1$ & \\
\hline Total & 30 & 100 & 92 & 100 & & & & 47 & 100 & 71 & 100 & & & \\
\hline $\begin{array}{l}\text { Medical treatment } \\
\text { for epilepsy }\end{array}$ & & & & & & & 0.2 & & & & & & & 0.7 \\
\hline Yes & 28 & 87.5 & 77 & 77.8 & 2.0 & $0.6-6.3$ & & 39 & 78.0 & 62 & 80.5 & 0.86 & $0.4-2.1$ & \\
\hline No & 4 & 12.5 & 22 & 22.2 & 1.0 & & & 11 & 22.0 & 15 & 19.5 & 1.0 & & \\
\hline Total & 32 & 100 & 99 & 100 & & & & 50 & 100 & 77 & 100 & & & \\
\hline Antiepileptic treatment & & & & & & & 0.8 & & & & & & & 0.3 \\
\hline Monotherapy & 18 & 75.0 & 39 & 78.0 & 1.0 & & & 19 & 73.1 & 38 & 82.6 & 1.0 & & \\
\hline Polytherapy & 6 & 25.0 & 11 & 22.0 & 1.2 & $0.4-3.7$ & & 7 & 26.9 & 8 & 17.4 & 1.7 & $0.5-5.5$ & \\
\hline Total & 24 & 100 & 50 & 100 & & & & 26 & 100 & 46 & 100 & & & \\
\hline Antiepileptic drugs & & & & & & & 0.3 & & & & & & & 0.6 \\
\hline Barbiturates & 21 & 87.5 & 39 & 78.8 & 1.0 & & & 20 & 76.9 & 38 & 82.6 & 1.0 & & \\
\hline No & 3 & 12.5 & 11 & 22.0 & 0.5 & $0.1-2.0$ & & 6 & 23.1 & 8 & 17.4 & 1.4 & $0.4-4.7$ & \\
\hline Yes & 32 & 100 & 50 & 100 & & & & 26 & 100 & 46 & 100 & & & \\
\hline Total & & & & & & & & & & & & & & \\
\hline Benzodiazepines & & & & & & & 0.06 & & & & & & & 0.1 \\
\hline No & 20 & 83.3 & 48 & 96.0 & 1.0 & & & 22 & 84.6 & 44 & 95.6 & 1.0 & & \\
\hline Yes & 4 & 16.7 & 2 & 4.0 & 4.8 & $0.8-28.3$ & & 4 & 15.4 & 2 & 4.4 & 4.0 & $0.7-23.5$ & \\
\hline Total & 24 & 100 & 50 & 100 & & & & 26 & 100 & 46 & 100 & & & \\
\hline Phenytoin & & & & & & & 0.9 & & & & & & & 0.4 \\
\hline No & 19 & 79.2 & 40 & 80.0 & 1.0 & & & 22 & 84.6 & 35 & 76.1 & 1.0 & & \\
\hline Yes & 5 & 20.8 & 10 & 20.0 & 1.1 & $0.3-3.5$ & & 4 & 15.4 & 11 & 23.9 & 0.6 & $0.2-2.0$ & \\
\hline Total & 24 & 100 & 50 & 100 & & & & 26 & 100 & 46 & 100 & & & \\
\hline Carbamazepine & & & & & & & 0.8 & & & & & & & 0.6 \\
\hline No & 10 & 41.7 & 19 & 38.0 & 1.0 & & & 12 & 46.9 & 18 & 39.1 & 1.0 & & \\
\hline Yes & 14 & 58.3 & 31 & 62.0 & 0.9 & $0.3-2.3$ & & 14 & 53.8 & 28 & 60.9 & 0.7 & $0.3-2.0$ & \\
\hline Total & 24 & 100 & 50 & 100 & & & & 26 & 100 & 46 & 100 & & & \\
\hline Valproate & & & & & & & 0.9 & & & & & & & 0.9 \\
\hline No & 21 & 87.5 & 43 & 86.0 & 1.0 & & & 23 & 88.5 & 41 & 89.1 & 1.0 & & \\
\hline Yes & 3 & 12.5 & 7 & 14.0 & 0.9 & $0.2-3.7$ & & 3 & 11.5 & 5 & 10.9 & 1.1 & $0.2-4.9$ & \\
\hline Total & 24 & 100 & 50 & 100 & & & & 26 & 100 & 46 & 100 & & & \\
\hline
\end{tabular}

${ }^{\dagger}$ OR: crude odds ratio; ${ }^{\ddagger} 95 \% \mathrm{Cl}$ : 95\% confidence interval. 
Table 3. Psychiatric comorbidity of people with epilepsy who were depressed $(n=32)$, not depressed $(n=99)$, anxious ( $n=50)$ and not anxious ( $n=77)$.

\begin{tabular}{|c|c|c|c|c|c|c|c|c|c|c|c|c|c|c|}
\hline \multirow[b]{3}{*}{ Variables } & \multicolumn{7}{|c|}{ Depression } & \multicolumn{7}{|c|}{ Anxiety } \\
\hline & \multicolumn{2}{|c|}{ Yes } & \multicolumn{2}{|c|}{ No } & \multirow[b]{2}{*}{$\mathrm{OR}^{+}$} & \multirow[b]{2}{*}{$95 \% \mathrm{Cl}^{\ddagger}$} & \multirow[b]{2}{*}{$P$ value } & \multicolumn{2}{|c|}{ Yes } & \multicolumn{2}{|c|}{ No } & \multirow[b]{2}{*}{$\mathrm{OR}^{+}$} & \multirow[b]{2}{*}{$95 \% \mathrm{Cl}^{\ddagger}$} & \multirow[b]{2}{*}{$P$ value } \\
\hline & $\mathrm{N}$ & $\%$ & $\mathrm{~N}$ & $\%$ & & & & $\mathrm{~N}$ & $\%$ & $\mathrm{~N}$ & $\%$ & & & \\
\hline $\mathrm{HAD}^{\S}$ Anxiety & & & & & & & $<0.0001$ & & & & & & & \\
\hline Negative & 10 & 32.3 & 66 & 70.2 & 1.0 & & & & & & & & & \\
\hline Positive & 21 & 67.7 & 28 & 29.8 & 4.9 & $2.1-11.8$ & & & & & & & & \\
\hline Total & 31 & 100 & 94 & 100 & & & & & & & & & & \\
\hline HAD ${ }^{\S}$ Depression & & & & & & & & & & & & & & $<0.0001$ \\
\hline Negative & & & & & & & & 28 & 57.1 & 66 & 86.8 & 1.0 & & \\
\hline Positive & & & & & & & & 21 & 42.9 & 10 & 13.2 & 4.9 & $2.1-11.8$ & \\
\hline Total & & & & & & & & 49 & 100 & 76 & 100 & & & \\
\hline GAS & & & & & & & 0.04 & & & & & & & 0.01 \\
\hline Mild (61-100) & 22 & 68.7 & 81 & 85.3 & 1.0 & & & 34 & 69.4 & 65 & 87.8 & 1.0 & & \\
\hline $\begin{array}{l}\text { Moderate / } \\
\text { Severe (0-60) }\end{array}$ & 10 & 31.3 & 14 & 14.7 & 2.6 & $1.0-6.7$ & & 15 & 30.6 & 9 & 12.2 & 3.2 & $1.3-8.0$ & \\
\hline Total & 32 & 100 & 95 & 100 & & & & 49 & 100 & 74 & 100 & & & \\
\hline $\begin{array}{l}\text { Suicidal thoughts } \\
\text { (during life) }\end{array}$ & & & & & & & $<0.0001$ & & & & & & & 0.001 \\
\hline No & 12 & 37.5 & 72 & 72.7 & 1.0 & & & 23 & 46.0 & 58 & 75.3 & 1.0 & & \\
\hline Yes & 20 & 62.5 & 27 & 27.3 & 4.4 & 1.9-10.3 & & 27 & 54.0 & 19 & 24.7 & 3.6 & $1.7-7.7$ & \\
\hline Total & 32 & 100 & 99 & 100 & & & & 50 & 100 & 77 & 100 & & & \\
\hline $\begin{array}{l}\text { Attempted suicide } \\
\text { (during life) }\end{array}$ & & & & & & & $<0.0001$ & & & & & & & 0.001 \\
\hline No & 23 & 71.9 & 95 & 96.0 & 1.0 & & & 39 & 78.0 & 74 & 96.1 & 1.0 & & \\
\hline Yes & 9 & 28.1 & 4 & 4.0 & 9.3 & $2.6-32.8$ & & 11 & 22.0 & 3 & 3.9 & 6.9 & $1.8-26.4$ & \\
\hline Total & 32 & 100 & 99 & 100 & & & & 50 & 100 & 77 & 100 & & & \\
\hline MINI & & & & & & & $<0.0001$ & & & & & & & $<0.0001$ \\
\hline $\begin{array}{l}\text { No psychiatric } \\
\text { diagnosis }\end{array}$ & 1 & 4.8 & 31 & 48.4 & 1.0 & & & 03 & 9.7 & 28 & 52.8 & 1.0 & & \\
\hline $\begin{array}{l}\text { At least one } \\
\text { psychiatric diagnosis }\end{array}$ & 20 & 95.2 & 33 & 51.6 & 18.8 & $2.4-148.5$ & & 28 & 90.3 & 25 & 47.2 & 10.4 & $2.8-38.6$ & \\
\hline Total & 21 & 100 & 64 & 100 & & & & 31 & 100 & 53 & 100 & & & \\
\hline $\begin{array}{l}\text { MINI (number } \\
\text { of diagnoses) }\end{array}$ & & & & & & & $<0.0001$ & & & & & & & $<0.0001$ \\
\hline None & 1 & 4.8 & 31 & 48.5 & 1.0 & & & 03 & 9.7 & 28 & 52.8 & 1.0 & & \\
\hline 1 & 10 & 47.6 & 21 & 32.8 & 14.8 & $1.7-124.1$ & & 13 & 41.9 & 18 & 34.0 & 6.7 & $1.7-27.0$ & \\
\hline 2 or more & 10 & 47.6 & 12 & 18.7 & 25.8 & $2.9-224.2$ & & 15 & 48.4 & 7 & 13.2 & 20.0 & $4.5-88.8$ & \\
\hline Total & 21 & 100 & 64 & 100 & & & & 31 & 100 & 53 & 100 & & & \\
\hline
\end{tabular}

${ }^{\dagger}$ OR: crude odds ratio; ${ }^{9} 95 \% \mathrm{Cl}$ : 95\% confidence interval; ${ }^{5} \mathrm{HAD}$ : Hospital Anxiety and Depression Scale; ${ }^{9} \mathrm{GAS}$ : Global Assessment Scale.

can be related to psychological sequela, and depression symptoms may influence the seizure frequency ${ }^{24,25}$. More recently, depression was thought to mediate the relationship between stress and anxiety and changes in seizure frequency ${ }^{26}$.

Consistent with the literature regarding suicide, this behavior was increased among those with depression and those with anxiety disorder ${ }^{27}$. Depression is well known to pose a risk on suicidal behavior ${ }^{28}$, as well as anxiety disorders ${ }^{27,29}$. Moreover, there is an increasing relationship between the number of mental disorders and suicidal behavior $^{29}$. Our findings also indicate an increased risk of depression and anxiety between people with epilepsy suffering from more than one psychiatric disease.

In a systematic review, lower socio-economic status was associated with higher rates of depressed mood and 
anxiety in youths ${ }^{30}$. Consistent with this result, individuals in the lowest economic group in our sample had at least four times the risk of anxiety, and subjects with less than four years of schooling had a higher risk of both depression and anxiety. These results are consistent with studies regarding depression and educational attainment ${ }^{31,32}$. Lower educational levels may lead to an accumulation of poor health outcomes associated with depression among people with in a lower social class, which is consistent with a review of socioeconomic factors and cardiovascular disease in the population ${ }^{33}$. They may also lack the necessary resources (social or financial) to cope with depression when it occurs ${ }^{34}$.

While it is necessary to improve the recognition and treatment of depression and anxiety in people with epilepsy, it is also important to face other changeable factors associated with mental suffering, especially in developing countries, such as socio-economic conditions and adequate treatment of epilepsy.

\section{REFERENCES}

1. Mensah SA, Beavis JM, Thapar AK, Kerr MP. A community study of the presence of anxiety disorder in people with epilepsy. Epilepsy Behav 2007;11: 118-124.

2. Mohammadi MR, Ghanizadeh A, Davidian H, Mohammadi M, Norouzian M. Prevalence of epilepsy and comorbidity of psychiatric disorders in Iran. Seizure 2006;15:476-482.

3. Tellez-Zenteno JF, Patten SB, Jette N, Williams J, Wiebe S. Psychiatric comorbidity in epilepsy: a population-based analysis. Epilepsia 2007;48:2336-2344.

4. Hermann BP, Seidenberg M, Bell B. Psychiatric comorbidity in chronic epilepsy: identification, consequences, and treatment of major depression. Epilepsia 2000;41(Suppl 2):S31-S41.

5. Barry JJ. The recognition and management of mood disorders as a comorbidity of epilepsy. Epilepsia 2003;44(Suppl 4):S30-S40.

6. Gilliam F, Hecimovic H, Sheline Y. Psychiatric comorbidity, health, and function in epilepsy. Epilepsy Behav 2003;44(Suppl 4):S26-S30.

7. O'Donoghue MF, Goodridge DM, Redhead K, Sander JW, Duncan JS. Assessing the psychosocial consequences of epilepsy: a community-based study. Br J Gen Pract 1999;49:211-214.

8. Jones JE, Hermann BP, Barry JJ, Gilliam FG, Kanner AM, Meador KJ. Rates and risk factors for suicide, suicidal ideation, and suicide attempts in chronic epilepsy. Epilepsy Behav 2003;44(Suppl 3):S31-S38.

9. Mensah SA, Beavis JM, Thapar AK, Kerr M. The presence and clinical implications of depression in a community population of adults with epilepsy. Epilepsy Behav 2006:8:213-219.

10. Adewuya AO, Ola BA. Prevalence of and risk factors for anxiety and depressive disorders in Nigerian adolescents with epilepsy. Epilepsy Behav 2005;6:342-347.

11. Johnson EK, Jones JE, Seidenberg M, Hermann BP. The relative impact of anxiety, depression, and clinical seizure features on health-related quality of life in epilepsy. Epilepsia 2004;45:544-550.

12. Nubukpo P, Preux PM, Houinato D, et al. Psychosocial issues in people with epilepsy in Togo and Benin (West Africa) I. Anxiety and depression measured using Goldberg's scale. Epilepsy Behav 2004;5:722-727.

13. Noronha AL, Borges MA, Marques LH, et al. Prevalence and pattern of epilepsy treatment in different socioeconomic classes in Brazil. Epilepsia 2007; 48:880-885.

14. Botega NJ, Bio MR, Zomignani MA, Garcia C Jr., Pereira WA. Mood disorders among inpatients in ambulatory and validation of the anxiety and depression scale HAD. Rev Saude Publica 1995;29:355-363.

15. Endicott J, Spitzer RL, Fleiss JL, Cohen J. The global assessment scale. A procedure for measuring overall severity of psychiatric disturbance. Arch Gen Psychiatry 1976;33:766-771.

16. Shirakawa I, Mari JJ, Chaves AC, Hisatsugo M. Family expectation, social adjustment and gender differences in a sample of schizophrenic patients. Rev Saude Publica 1996;30:205-212.

17. Amorim P. Mini International Neuropsychiatric Interview (MINI): validation of a short structured diagnostic psychiatric interview. Rev Bras Psiquiatr 2000;22:106-115.

18. ABEP. Critério Padrão de Classificação Econômica do Brasil/2008. São Paulo: Associação Brasileira de Empresas de Pesquisa (Brazilian Association of Research Companies); 2007.

19. Bjelland I, Dahl AA, Haug TT, Neckelmann D. The validity of the Hospital Anxiety and Depression Scale. An updated literature review. J Psychosom Res 2002:52:69-77.

20. Kessler RC, Ustun TB. The World Mental Health (WMH) Survey Initiative Version of the World Health Organization (WHO) Composite International Diagnostic Interview (CIDI). Int J Methods Psychiatr Res 2004;13:93-121.

21. Mackinnon A, Christensen H, Jorm AF, Henderson AS, Scott R, Korten AE. A latent trait analysis of an inventory designed to detect symptoms of anxiety and depression using an elderly community sample. Psychol Med 1994; 24:977-986.

22. Jacoby A, Baker GA, Steen N, Potts P, Chadwick DW. The clinical course of epilepsy and its psychosocial correlates: findings from a U.K. Community study. Epilepsia 1996;37:148-161.

23. Mbuba CK, Ngugi AK, Newton CR, Carter JA. The epilepsy treatment gap in developing countries: a systematic review of the magnitude, causes, and intervention strategies. Epilepsia 2008;49:1491-1503.

24. Kanner AM, Balabanov A. Depression and epilepsy: how closely related are they? Neurology 2002;58(Suppl 5):S27-S39.

25. Thapar A, Roland M, Harold G. Do depression symptoms predict seizure frequency--or vice versa? J Psychosom Res 2005;59:269-274.

26. Thapar A, Kerr M, Harold G. Stress, anxiety, depression, and epilepsy: investigating the relationship between psychological factors and seizures. Epilepsy Behav 2009;14:134-140.

27. Norton PJ, Temple SR, Pettit JW. Suicidal ideation and anxiety disorders: elevated risk or artifact of comorbid depression? J Behav Ther Exp Psychiatry 2008;39:515-525.

28. Kessler RC, Borges G, Walters EE. Prevalence of and risk factors for lifetime suicide attempts in the National Comorbidity Survey. Arch Gen Psychiatry 1999;56:617-626.

29. Lee S, Fung SC, Tsang A, et al. Lifetime prevalence of suicide ideation, plan, and attempt in metropolitan China. Acta Psychiatr Scand 2007;1 16:429-437.

30. Lemstra M, Neudorf C, D'Arcy C, Kunst A, Warren LM, Bennett NR. A systematic review of depressed mood and anxiety by SES in youth aged 10-15 years. Can J Public Health 2008;99:125-129.

31. Lorant V, Deliege D, Eaton W, Robert A, Philippot P, Ansseau M. Socioeconomic inequalities in depression: a meta-analysis. Am J Epidemiol 2003; 157:98-112.

32. Mezuk B, Eaton WW, Golden SH, Ding Y. The influence of educational attainment on depression and risk of type 2 diabetes. Am J Public Health 2008:98:1480-1485.

33. Kaplan GA, Keil JE. Socioeconomic factors and cardiovascular disease: a review of the literature. Circulation 1993;88:1973-1998.

34. Thurston RC, Kubzansky LD, Kawachi I, Berkman LF. Do depression and anxiety mediate the link between educational attainment and CHD? Psychosom Med 2006;68:25-32. 